Products and Services In Practice is provided to readers using text and images from the manufacturer, supplier or distributor and does not imply endorsement by $B D J$ In Practice. Normal and prudent research should be exercised before purchase or use of any product mentioned.

Please send product and services news through to David Westgarth, BDJ In Practice via: David.Westgarth@bda.org

\section{Patient generation engine launched}

IAS Academy has launched a brand-new patient generation engine designed to help its members find new patients and grow their ortho-restorative businesses.

It is running a national advertising campaign to attract new patient enquiries, which it will direct to IAS members to follow-up on. Not only will this provide invaluable promotion for the relevant treatment modalities, but it will also support GDPs by providing a potential new revenue stream.

For IAS Academy members to take advantage of this new feature, don't forget to:

$\rightarrow$ Log into your IAS account and update your practice details for the dentist locator

$\rightarrow$ Respond to enquiries quickly

$\rightarrow$ Use the email template provided to communicate with patients

$\rightarrow$ Follow up with a call and/or text.

Not an IAS member? Join the Academy today!

For more information on IAS Academy membership and upcoming training courses visit www.iasortho.com, email courses@iasortho.com or call 01932 336470 (Press 1).

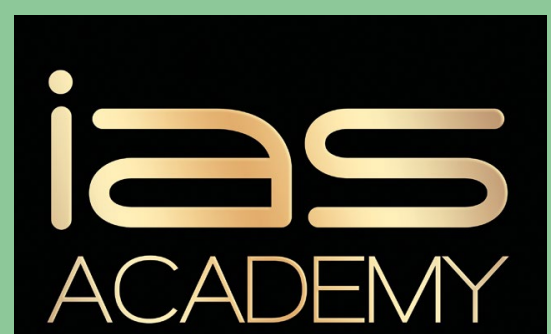

M E M B E R S H I P

\title{
No one-size-fits-all biomaterial
}

There is no one-size-fits-all biomaterial. This means clinicians need access to a range of solutions in order to find the best option for each individual case.

The Straumann Group understands this, which is why it offers a comprehensive and flexible portfolio of evidence-based biomaterials that cater for multiple indications. It consists of xenograft, allograft and synthetic graft materials, as well as resorbable and non-resorbable barrier membranes.

Among them is the Straumann Emdogain designed to accelerate soft tissue formation for reduced wound complications, enhanced patient comfort and less postsurgical swelling.

To find out more about this and many other biomaterials available, visit www.straumann-uk.co/biomaterials.

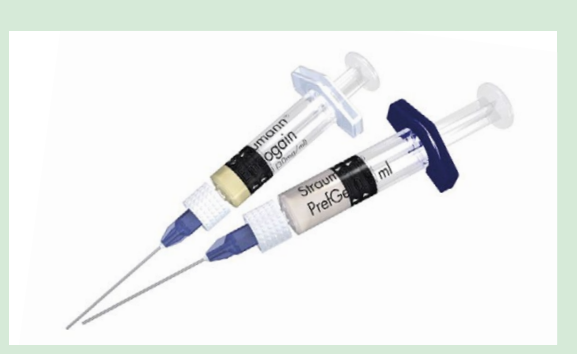

\section{Communication course helps dental teams secure} \section{success in 2021}

2020 robbed many of us of one of the most fundamental things we crave - human contact and connection - with lockdowns and restrictions to our daily lives having a huge impact on mental health and leaving many people feeling isolated, afraid and alone.

As we head into 2021 with yet more uncertainty ahead of us, Dr Barry Oulton, a highly experienced dentist, lecturer, trainer and business man, is encouraging dental teams to put building rapport with their patients at the forefront.

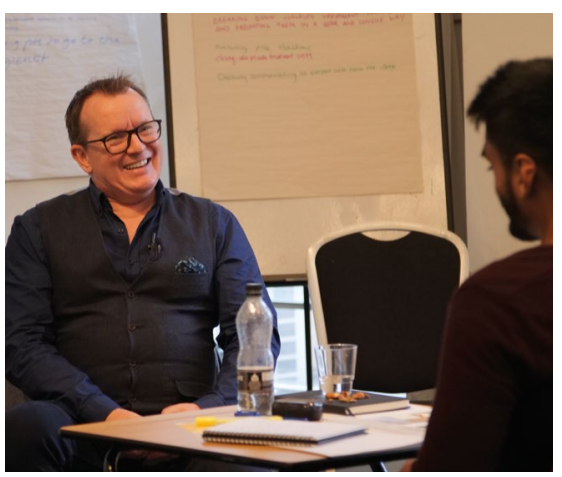

His two-day course, Influencing Smiles, is a powerful lesson in communication and sales which teaches principal dentists and their teams how to sell with integrity and communicate with confidence.

It helps dentists boost their confidence and reduce conflict and complaints in their practices at the same time as improving their interactions with patients and boosting treatment uptake by facilitating clearer discussions around options and costs.

Upcoming events for 2021 (depending on COVID-19 restrictions) include:

$\rightarrow 12$ and 13 March - Birmingham

$\rightarrow 14$ and 15 May - London

$\rightarrow 11$ and 12 June - Birmingham

$\rightarrow 24$ and 25 Sept - London

$\rightarrow 15$ and 16 Oct - Birmingham.

Courses run from 9am-6pm on Friday and $8 \mathrm{am}$ to $5 \mathrm{pm}$ on Saturday.

For further details, please visit www. theconfidentdentist.com or call 0333220 2447 or email sally@theconfidentdentist.com. 